\title{
Supervisory Support as Moderator between Work Family Conflict and Turnover Intentions
}

\author{
Aneel Kumar ${ }^{1 *}$, Khalil Ahmed Channa ${ }^{2}$, Niaz Ahmed Bhutto ${ }^{2}$
}

\begin{abstract}
:
The purpose of this research is to investigate supervisory support as moderator between work family conflict (WFC) and turnover intentions in banking sector employees, working in Sindh province of Pakistan. Primary data were collected through Likert type survey questionnaire, targeting the 181 employees, working in commercial banks. The findings of this study shows the significant positive effect of work family conflict on turnover intentions of employees. Moreover, supervisory support was found as the significant moderator of the relationship between work family conflict and turnover intentions. The moderating effect of supervisory support significantly reduced the turnover intentions level of employees which they experienced due to work family conflict.
\end{abstract}

Keywords: Work Family Conflict, Supervisory Support, Turnover Intentions.

\section{Introduction}

The environment in banking sector of Pakistan is very challenging. It is a routine for employee to work late hours. Employees hardly leave their job before sunset. Due to cut-throat competitions, customer are given more than due care. In most of the banks, particularly in the area focused in current study, customers are allowed to deposit and withdraw amount even after official work hours. In such circumstances it becomes very difficult for employees to fulfill their family role demands, and as a result they are likely to face conflict between their work and family demands. In organizational behavior literature such inter-role conflict is termed as work family conflict (WFC). Netemeyer, et al. (1996) defines WFC as "a form of inter-role conflict in which the general demands of time devoted to, and strain created by the job interfere with performing family-related responsibilities" ( P. 401). WFC has been tested as the significant predictor of many work place attitudes and behaviors and one of the potential outcome of WFC in the workplace is turnover intentions (Amstad, Meier, Fasel, Elfering, \& Semmer, 2011; Dinger, Thatcher, \& Stepina, 2010; Haar, Roche, \& Taylor, 2012; Pasupuleti, Allen, Lambert, \& Cluse-Tolar, 2009). Further, WFC has also been tested as significant predictors of some workplace outcomes in context of Pakistan such as employees' performance (Ashfaq, Mahmood, \& Ahmad, 2013), job satisfaction (Ahmed \& Muhammad Muddasar, 2012) but little attention has been given to the role of WFC in https://doi.org/10.30537/sijmb.v4i2.107

${ }^{1}$ Department of Commerce, Shah Abdul Latif University, Khairpur Mir's

* Corresponding Author: aneel.kumar@salu.edu.pk

2 Department of Business Administration, Sukkur IBA University 
developing turnover intentions. Therefore, this study tends to investigate the effect of WFC on the turnover intentions. Further, job demand resource model (Demerouti, Bakker, Nachreiner, \& Schaufeli, 2001) posits that if employees are provided resources in the workplace than such resources can counter the effect of job demands. This model proposes supervisory support as one of the potential resource for managing the work role demands of employees. Furthermore, the research on context of current study shows that corporate sector of Pakistan, including the banking sector, is at stage of infancy in adopting the human resources management (HRM) practices and due to such ineffective HRM practices, employees form groups with each other for seeking help. However, managers of banks have been trying to implement the HRM practices informally (Khilji, 2013). Further, the collectivist cultural context of the current study (Hofstede, 2016) can be the added advantage, which can let us presume that supervisors can be very helpful for employees to reduce their turnover intentions. Therefore, based on the job demand resource model (Demerouti et al., 2001), and collectivist cultural context (Hofstede, 2016; Khilji, 2013), we argue that if employees are provided social support resources such as supervisory support then employees turnover intention level developed due to WFC can be decreased. Therefore, the overall objective of this research is to investigate supervisory support as the moderator between WFC and turnover intentions in the employees of banking sector of Sindh, Pakistan.

\section{Theoretical Framework and Hypotheses}

One of the initial works on work family conflict (WFC) by Greenhaus \& Beutell (1985) defines WFC as "a form of role conflict in which the role pressures from work and family domains are mutually incompatible in some respect that is participation in the work (family) role is made more difficult by virtue of participation in the family (work) role" (p. 77). Further, Gutek et al. (1991) argues that as WFC is related to two domains i.e., work and family. Therefore, they propose that WFC can be two directional i.e., work interference with family (WIF) and family interference with work (FIW). If conflict is initiated from work place and it does not allow an individual to perform family role, then such conflict is termed as WIF. Further, if conflict is initiated from home and it does not allow an individual to perform work role, then such conflict is termed as FIW. Furthermore, to measure these both direction of WFC, Netemeyer, et al. (1996) developed the scale which measures both directions of WFC but they called WIF as WFC and FIW as family-work Conflict. They defines WFC as "a form of interrole conflict in which the general demands of time devoted to, and strain created by the job interfere with performing family-related responsibilities" ( P. 401). This study investigates WFC rather than FWC due to the focus of this study which was to contribute in the organizational context of employees, rather than the home context. WFC has been tested as the significant predictor of many work place attitudes and behaviors such as psychological strain (Kalliath, Hughes, \& Newcombe, 2011), turnover intentions (Haar et al., 2012). turnover intentions, (Amstad et al., 2011). Although, WFC has been tested as predictor of turnover intentions (Amstad et al., 2011; Dinger et al., 2010; Haar et al., 2012; Pasupuleti et al., 2009) and WFC has also been

Sukkur IBA Journal of Management and Business - SIJMB | Volume 4 No. 2 July - December 2017 @ Sukkur IBA University 
tested as the predictor of some work related outcomes in context of Pakistan such as employees' performance (Ashfaq et al., 2013), job satisfaction (Ahmed \& Muhammad Muddasar, 2012) but it has hardly been tested as predictor of turnover intentions. SamGnanakkan (2010) describes turnover intentions as the employees' thoughts about leaving an organization. Turnover intentions is actually a step to actual resignation (Alexander, Lichtenstein, Oh, \& Ullman, 1998). Cinamon \& Rich (2002) suggested that people who value their family may also show responsibility at work because of getting some extra financial benefit from their organization and as a result, the extra effort put to workplace creates stress and leads to turnover intentions. Therefore, based on these studies, we may argue that the negative experiences of WFC can create the intentions of turnover. Further, we argue that on the one hand, the environment in banking sector of Pakistan is very challenging. It is routine for employees to work late hours. Employees hardy leave their job before sunset. Due to cut-throat competitions customer are given more than due care. In most of the banks, particularly in the area focused in current study i.e., Sukkur, Khairpur districts of Sindh province of Pakistan, customers are allowed to deposit and withdraw amounts even after official work hours. In such circumstances it becomes very difficult for employees to fulfill their family role demands. On the other hand, the majority of people in Pakistan lives in joint family setup (Itrat, Taqui, Qazi, \& Qidwai, 2007), where individuals not only take care of their wife and children but they also take care of the demands of their parents and other family members as well. In such circumstances, it is likely that employees will experience WFC which can develop the turnover intentions in the employees. Therefore, we propose that;

Hypothesis 1: Work family conflict significantly increases the turnover intentions level of employees.

Work family conflict theory (Greenhaus \& Beutell, 1985) posits job demands as the one of the prime sources of WFC among the employees. Furthermore, the job demand resource model (Demerouti et al., 2001) posits that the work place resources can be used as the mechanism to counter the work demands. One of the resource is the supervisory support. Supervisory support is considered as the social support resource. This research has focused on the supervisory support as the resource based on job demand resource model and due to the collectivist cultural context of current study (Hofstede, 2016; Khilji, 2013). People living in collectivist cultural context are likely to offer love, support to each other and the lack of social resources such as supervisory support can lead to employees to make the decisions like withdrawal form job as the ultimate solution (Demerouti et al., 2001). Employees consider their supervisors as the agents of organization and they can play a significant role in retention of employees (Eisenberger, Stinglhamber, Vandenberghe, Sucharski, \& Rhoades, 2002). Being agents of the organization, they have got some authority to help employees to meet their work demands. Further, they can provide information to employees, regarding the organizational work family policies, they can interact with employees and listen to their

Sukkur IBA Journal of Management and Business - SIJMB | Volume 4 No. 2 July - December 2017 @ Sukkur IBA University 
personal problems (Allen, Amason, \& Holmes, 1998). Therefore, based on the job demand resource model, and collectivist cultural context of this study, we argue that if the supervisor is supportive then employee's turnover intentions level developed due to WFC can be decreased. Although supervisory support is already tested and found as significant moderator in work family conflict studies such as between work demands and WFC (Yildirim \& Aycan, 2008), between job control, work overload and WFC (Warner \& Hausdorf, 2009), it is rare to find any study testing supervisory support as moderator between WFC and turnover intentions. Thus, we propose that,

Hypothesis 2: Supervisory support moderates the positive relationship between work family conflict and turnover intentions such that the positive relationship will be weaker when supervisory support is high as compared to when supervisory support is low.

\section{Research Model}

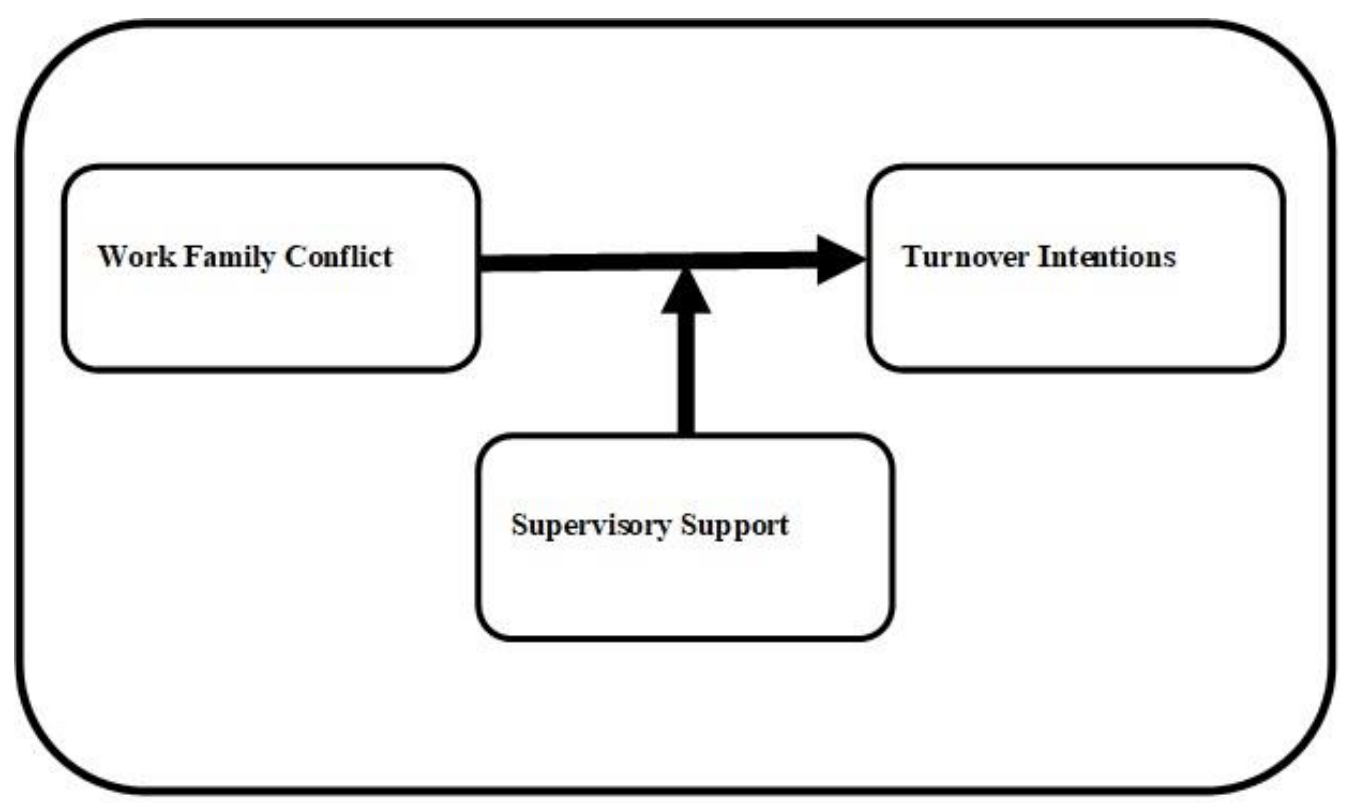

Figure 1: Research Model

\section{Research Methodology}

\subsection{Sample}

The primary data for this study were collected form the employees of banking sector of Sindh province of Pakistan. Data were mainly collected from two districts i.e., Sukkur and Sindh. Although, around 300 questionnaires were distributed but some respondents either did not return the questionnaire even after two visits or some did not properly fill the questionnaire. We did not force any respondent to fill the questionnaire. They were given open choice to participate or do not participate in the study. Therefore, only 181 
properly filled questionnaires were included in the current study which makes a healthy response rate of around 60 percent. The demographic information of respondents is given in table 01 .

Table 01: Respondents Demographics (N=181)

\begin{tabular}{lrc}
\hline Demographic Variable & N & Percentage \\
\hline Gender & & \\
Male & 136 & 75.0 \\
Female & 45 & 25.0 \\
Age (In Years) & & 50.8 \\
$20-29$ & 92 & \\
& & 37.0 \\
$30-39$ & 67 & 11.0 \\
$40-49$ & 20 & 01.1 \\
Above 50 & 02 & \\
Experience (In years) & & 12.7 \\
$01<02$ & 23 & 61.3 \\
$02<05$ & 111 & 17.1 \\
$05<10$ & 31 & 08.8 \\
10 and above & 16 & \\
\hline
\end{tabular}

\subsection{Measures}

A five point Likert scale questionnaire is used for conducting survey for data collection. WFC is measured by five items' scale adopted from the study of Netemeyer, et al. (1996). Turnover intentions is measured by a four items' scale adopted from Kelloway, et al. (1999). Supervisory support is measured through a five items' scale adopted from Allen et al. (1998).

\section{Data Analysis and Results}

Initially we performed preliminary data screening tests (Pallant, 2010). It is very important to perform these tests before the analysis of results such as the presence of outliers may distort the results. The existence of missing values or aberrant values may provide alternative explanations. Further, confirmatory factor analysis (CFA) was conducted to assess the independent structure of the data and the fit of measures in context of current study. Model fit indices, recommended by Hair, et al. (2010) were followed. Comparative Fit Index (CFI) and Tucker-Lewis Index (TLI) value of .90 or above and Root-Mean Square Error of Approximation (RMSEA) value less than 0.08 are considered as good fit for any model. CFA results show that our model best fits the data as all the fit indices were well above the threshold values $(\mathrm{CMIN} / \mathrm{DF}=1.16, \mathrm{CFI}=$ 97 , TLI $=.96$, RMSEA=.03). We also checked the reliability of variables. This followed the descriptive statistical techniques that were applied to determine mean, standard deviation, correlations. Finally, regression analysis, through modprobe macro (Hayes 
\& Matthes, 2009) were conducted to test the main effect of WFC on turnover intentions and the moderating effect of supervisory support. The results of mean, standard deviation and reliability are given in table 02 . Although 0.7 is considered as an excellent value for reliability of a construct, however an score of 0.5 and above indicates the acceptability and a score of 0.6 is considered as good (Gliem \& Gliem, 2003). Therefore, all the constructs, included in current study are well within the acceptable level.

Table 02: Mean, Standard Deviation and Reliability

\begin{tabular}{lccc}
\hline \multicolumn{1}{c}{ Alpha Coefficient } & Mean & St. Deviation & \\
\hline Work Family Conflict (WFC) & 4.03 & .52 & .63 \\
& & & .72 \\
Supervisory Support & 3.19 & .68 & .75 \\
Turnover Intentions & 4.10 & .57 &
\end{tabular}

Correlation result between WFC and turnover intentions were significant $(r=.30, p<$ .01 ). The correlation of supervisory support with WFC and turnover intentions were insignificant. The correlation of demographics (i.e., gender, age, experience) with the turnover intentions were insignificant therefore, these were not included in further regression analysis. Correlation results are given in table 03.

Table 03: Correlation Matrix

\begin{tabular}{|c|c|c|c|c|c|c|}
\hline & 1 & 2 & 3 & 4 & 5 & 6 \\
\hline 1. Gender & 1 & & & & & \\
\hline 2. Age & $-.21^{* *}$ & 1 & & & & \\
\hline 3. Experience & $-.18^{*}$ & $.62^{* *}$ & 1 & & & \\
\hline 4. Work Family Conflict & .04 & .13 & .11 & 1 & & \\
\hline 5. Supervisory Support & .09 & $-.19^{* *}$ & -.09 & -.02 & 1 & \\
\hline 6. Turnover Intentions & .03 & .04 & -.07 & $.30^{* *}$ & .07 & 1 \\
\hline
\end{tabular}

Subsequently, regression results showed that WFC has significant effect on turnover intentions $(\beta=.28, p<.01)$. Therefore, $\mathrm{H} 1$ was fully supported. Furthermore, the interactive effect of WFC and supervisory support on turnover intentions was also significant $(\beta=-.37, \mathrm{p}<.01)$. Therefore, $\mathrm{H} 2$ was also fully supported. Overall, model explained around 15 percent of significant variance in turnover intentions of the employees and the change in r-square due to moderating effect was around 05 percent 
Aneel Kumar (et al.) / Supervisory Support as Moderator between Work Family Conflict and Turnover Intentions

which was also significant. These results are given in table 04 .

Table 04: Main effect of work family conflict and moderating effect of supervisory support on turnover intentions

\begin{tabular}{clll}
\hline $\begin{array}{c}\text { Independent Variables } \\
\mathrm{p}\end{array}$ & $\beta$ & Std. Error & $\mathrm{t}$ \\
\hline $\begin{array}{c}\text { Work family conflict } \\
.00^{* * *}\end{array}$ & .28 & .07 & 3.6 \\
$\begin{array}{l}\text { Supervisory Support } \\
.23\end{array}$ & .07 & .05 & 1.18 \\
$\begin{array}{l}\text { WFC X Supervisory Support } \\
.0015^{* *}\end{array}$ & -.37 & .11 & -3.22 \\
\hline
\end{tabular}

Dependent Variable: Turnover Intentions

R-Square: .15; R-Square change due to moderation: .05

F - Value: 10.36; Significance level: $* *=.00$

Furthermore, slopes were drawn to check the effects of moderator (i.e., supervisory support) on the relationship between WFC and turnover intentions at different levels of moderators. The slope showed that the level of turnover intentions increased as WFC increased, when supervisory support was low. The level of turnover intentions decreased as WFC increased, when supervisory support was high. These results are consistent with our hypothesis 2 for interactive effects of WFC and supervisory support on turnover intension. The Slope is given in figures 2.

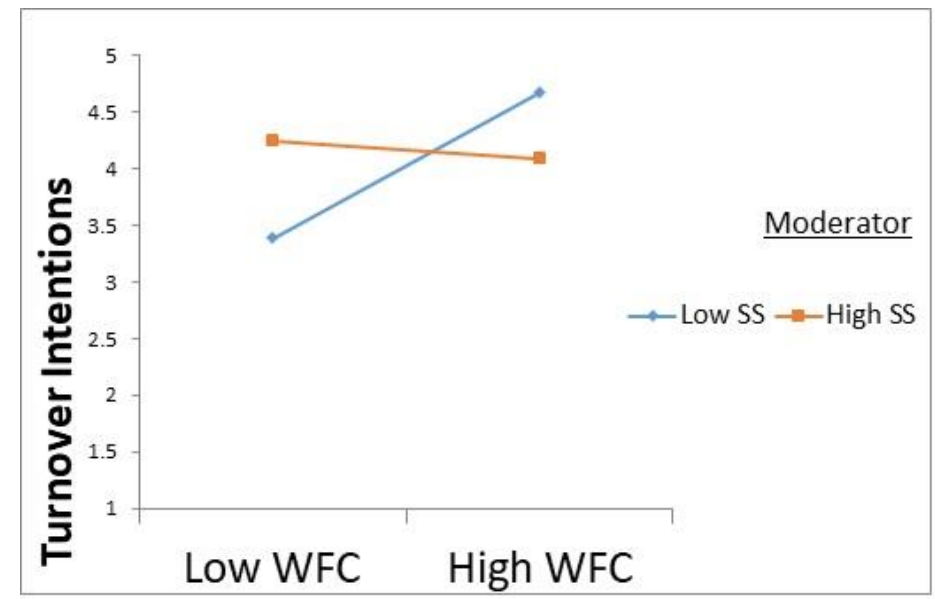

Figure 2: Slope for the Interactive Effect of Work Family Conflict (WFC) and Supervisory Support (SS) on Turnover Intentions

\section{Discussion}

The results of this study showed existence of WFC in the employees. The reasons for existence of WFC could be larger growing number of banks branches as compared to

Sukkur IBA Journal of Management and Business - SIJMB | Volume 4 No. 2 July - December 2017 @ Sukkur IBA University 
increase in customers. To keep good relations with customers, banks facilitate their customers even after official work hours, which does not allow employees to go to their homes timely, and resultantly it is creating the WFC in the employees of banking sector. The employees' perceptions regarding turnover intentions were also high. The reasons for turnover intentions of employees could be the growing number of new banks and their branches and extra work hours without pay that employees perform in routine. Further, the results of this study showed that WFC has significant effect on turnover intentions of the employees of banking sector. These results are also consistent with the studies testing effect of WFC on turnover intentions (Amstad et al., 2011; Dinger et al., 2010; Haar et al., 2012; Pasupuleti et al., 2009).

Furthermore, based on demand resource model (Demerouti et al., 2001), we proposed supervisory support as the moderator between WFC and turnover intentions. Our results showed that supervisory support significantly moderates the relationship between WFC and turnover intentions as we proposed. The role of supervisory support as moderator was found very effective to reduce the turnover intentions level of employees experienced due to WFC. The interactive effect of supervisory support with WFC not just made the relationship between WFC and turnover intentions weaker but actually the supervisory support's moderating effect changed the direction of the relationship from positive to negative, which shows the influential role of supervisory support as moderator. Such strong influence of moderator can be due to the collectivist cultural context of Pakistan (Hofstede, 2016; Khilji, 2013).

\subsection{Theoretical and Managerial Implications}

This research contributed theoretically by incorporating the WFC theory (Greenhaus \& Beutell, 1985) and demand resource model (Demerouti et al., 2001) in context of Pakistan. From the managerial implications point of view, this research recommends that the employees of banking sector are experiencing WFC and such negative experiences are developing the turnover intentions. Environment in banking sector of Pakistan is very competitive which results in heavy workload on employees (Kumar \& Arain, 2014). Further, even there is no limit of time and employees are likely to work long work hours beyond the specific job timings (Bashir \& Ismail Ramay, 2010). As a result, it becomes very difficult for employees to balance their work and family role (Kumar, Channa, \& Bhutto, 2017). This study can be considered as the wakeup call for the banking sector organizations to pay serious attentions to the issue of work family conflict arising. Loyal employees are the long term asset of an organization. Human resources practices in organizations of Pakistan or even in banking sector are at the stage of infancy (Khilji, 2013). Further, the policies for just the work role of an employee may not work anymore and organizations should also develop the policies and programs which provide support for managing the family role responsibilities of an employee. If measures are not taken by the banking sector organization, the turnover intentions developed due to experiences of WFC can lead to actual turnover. Based on the results of this study, this research suggests that in absences of effective human

Sukkur IBA Journal of Management and Business - SIJMB | Volume 4 No. 2 July - December 2017 () Sukkur IBA University 
resources management practices and work family policies, the resource of supervisory support can be very helpful to reduce the turnover intentions of employees. Employees consider their supervisors as the agents of organization and they can play a significant role in retention of employees (Eisenberger et al., 2002). Therefore, organizations should also provide training opportunities to supervisors. Further, supervisors may be provided detailed information, regarding the work family policies of organization, for effective management of the work family role of employees. At the time when employees are experiencing WFC or when such negative experiences are developing turnover intentions, supervisors with their interpersonal skills, by providing work family policies related information to employees and discussing with employees their personal problems can work like a savior for the employees to reduce their turnover intentions.

\subsection{Limitations and Future Directions}

The cross-sectional data were used in the current study which may not establish the casual effects. Therefore, the future research may use longitudinal data. The other potential moderators such as coworkers' support, organizational support can be used in the relationship between WFC and turnover intentions because these are also considered as the potential sources of social support. The other possible outcomes of WFC such as job satisfaction, burnout, can be tested. It could provide the interesting insights to test the WFC and family work conflict together and comparing their effects. Other studies may take job demands, proposed in job demand resource model and test their effect on WFC of employees. The other potential antecedent of turnover intentions such as target oriented banking can be tested. Further, it can be studied that do the turnover intention is converted into real turnover or not. Moreover, it should be tested in other sectors of Pakistan for more generalizable results, as results of this study are limited only to banking sector employees.

\section{References}

Ahmed, M., \& Muhammad Muddasar, S. (2012). The impact of work-family conflict and pay on employee job satisfaction with the moderating affect of perceived supervisor support in Pakistan banking sector. Global Journal of Management and Business Research, 12(6).

Alexander, J. A., Lichtenstein, R., Oh, H. J., \& Ullman, E. (1998). A causal model of voluntary turnover among nursing personnel in long-term psychiatric settings. Research in Nursing and Health, 21(5), 415-428.

Allen, M. W., Amason, P., \& Holmes, S. (1998). Social support, Hispanic emotional acculturative stress and gender. Communication Studies, 49(2), 139-157. doi: 10.1080/10510979809368525

Amstad, F. T., Meier, L. L., Fasel, U., Elfering, A., \& Semmer, N. K. (2011). A metaanalysis of work-family conflict and various outcomes with a special emphasis on cross-domain versus matching-domain relations. Journal of Occupational Health Psychology, 16(2), 151. 
Ashfaq, S., Mahmood, Z., \& Ahmad, M. (2013). Impact of Work-Life Conflict and Work over Load on Employee Performance in Banking Sector of Pakistan. Middle-East Journal of Scientific Research, 14(5), 688-695.

Bashir, U., \& Ismail Ramay, M. (2010). Impact of stress on employees job performance: A study on banking sector of Pakistan. Bashir, U., \& Ramay, MI (2010). Impact Of Stress On Employees Job Performance A Study On Banking Sector Of Pakistan. International Journal of Marketing Studies, 2(1), 122-126.

Cinamon, R. G., \& Rich, Y. (2002). Profiles of attribution of importance to life roles and their implications for the work-family conflict. Journal of Counseling Psychology, 49(2), 212.

Demerouti, E., Bakker, A. B., Nachreiner, F., \& Schaufeli, W. B. (2001). The job demands-resources model of burnout. Journal of Applied Psychology, 86(3), 499.

Dinger, M., Thatcher, J. B., \& Stepina, L. P. (2010). A Study of Work-Family Conflict Among IT Professionals: Job Characteristics, Individual Values, and Management Practices. Journal of Organizational Computing and Electronic Commerce, 20(1), 91-121. doi: 10.1080/10919390903482341

Eisenberger, R., Stinglhamber, F., Vandenberghe, C., Sucharski, I. L., \& Rhoades, L. (2002). Perceived supervisor support: contributions to perceived organizational support and employee retention. Journal of Applied Psychology, 87(3), 565.

Gliem, J. A., \& Gliem, R. R. (2003). Calculating, interpreting, and reporting, cronbach's alpha reliability coefficient for likert-type scales. Paper presented at the Proceedings of the Midwest Research to Practice Conference in Adult Continuing and Community Education, Columbus, $\mathrm{OH}$.

Greenhaus, J. H., \& Beutell, N. J. (1985). Sources of conflict between work and family roles. Academy of Management Review, 10(1), 76-88.

Gutek, B., Searle, S., \& Klepa, L. (1991). Rational versus gender role-explanations for work-family conflict. Journal of Applied Psychology, 76, 560-568.

Haar, J. M., Roche, M., \& Taylor, D. (2012). Work-family conflict and turnover intentions of indigenous employees: the importance of the whanau/family for Maori. The International Journal of Human Resource Management, 23(12), 2546-2560.

Hair, J. F., Black, W. C., Babin, B. J., \& Anderson, R. E. (2010). Multivariate data analysis (7 ed.). Upper Saddle River, NJ: Prentice Hall.

Hayes, A. F., \& Matthes, J. (2009). Computational procedures for probing interactions in OLS and logistic regression: SPSS and SAS implementations. Behavior Research Methods, 41(3), 924-936.

Hofstede, G. (2016). from http://geert-hofstede.com/pakistan.html

Itrat, A., Taqui, A. M., Qazi, F., \& Qidwai, W. (2007). Family systems: perceptions of elderly patients and their attendents presenting at a university hospital in Karachi, Pakistan. Journal of pakistan medical association, 57(2), 106.

Kalliath, P., Hughes, M., \& Newcombe, P. (2011). When Work and Family are in Conflict: Impact on Psychological Strain Experienced by Social Workers in 
Aneel Kumar (et al.) / Supervisory Support as Moderator between Work Family Conflict and Turnover

Australia. Australian Social Work, 65(3), 355-371. doi: 10.1080/0312407x.2011.625035

Kelloway, E. K., Gottlieb, B. H., \& Barham, L. (1999). The source, nature, and direction of work and family conflict: a longitudinal investigation. Journal of Occupational Health Psychology, 4(4), 337.

Khilji, S. E. (2013). Human resource management in Pakistan. In P. S. Budhwar \& Y. A. Debrah (Eds.), Human resource management in developing countries (pp. 102-120): Routledge.

Kumar, A., \& Arain, G. A. (2014). Testing Main and Interactive Effect of Personal Coping and Social Support on Work Family conflict. Sukkur IBA Journal of Management and Business, 01(01), 87-101.

Kumar, A., Channa, K. A., \& Bhutto, N. A. (2017). Gender as Moderator of the Relationship between Supervisory Support and Work to Family Enrichment. Global Management Journal for Academic \& Corporate Studies, 7(1), 103109.

Netemeyer, R. G., Boles, J. S., \& McMurrian, R. (1996). Development and validation of work-family conflict and family-work conflict scales. Journal of Applied Psychology, 81, 400-410.

Pallant, J. (2010). SPSS survival manual: A step by step guide to data analysis using SPSS: Open University Press.

Pasupuleti, S., Allen, R. I., Lambert, E. G., \& Cluse-Tolar, T. (2009). The impact of work stressors on the life satisfaction of social service workers: A preliminary study. Administration in Social Work, 33(3), 319-339.

SamGnanakkan, S. (2010). Mediating role of organizational commitment on HR practices and turnover intention among ICT professionals. Journal of Management Research, 10(1), 39.

Warner, M. A., \& Hausdorf, P. A. (2009). Understanding work-to-family conflict: the role of organization and supervisor support for work-life issues. Organization Management Journal, 6(3), 130-145.

Yildirim, D., \& Aycan, Z. (2008). Nurses' work demands and work-family conflict: A questionnaire survey. International Journal of Nursing Studies, 45(9), 13661378. doi: 10.1016/j.ijnurstu.2007.10.010 